\title{
The Medico-Legal Importance of Establishing Human Identity by Palatal Rugoscopy: Evaluation of the Immutability and Individuality of Palatal Rugae under the Influence of Ante Mortem Orthodontic Treatment
}

\author{
Gonçalves $\mathrm{AF}^{1}$, Diamantino $\mathrm{F}^{2,3}$, Pestana $\mathrm{D}^{2,3}$, and Palmela Pereira $\mathrm{C}^{* 3,4,5}$ \\ ${ }^{1}$ Dental Private Practitioner, Master Thesis, Faculty of Dentistry from University of Lisbon, Portugal \\ ${ }^{2}$ Full Professor, Department of Statistics and Operation Research, Faculty of Sciences, University of Lisbon, Portugal \\ ${ }^{3}$ Investigator from the Center of Statistics and Applications of University of Lisbon (CEAUL), Portugal \\ ${ }^{4}$ Professor, Faculty of Dentistry from University of Lisbon Consultant of Forensic Dentistry South Branch from \\ Portuguese National Institute of Legal Medicine and Forensic Sciences, Portugal \\ ${ }^{5}$ Investigator from the CENCIFOR, Center of Forensic Studies, Portugal
}

${ }^{*}$ Corresponding author: Palmela Pereira C, South delegation from the National Institute of Legal Medicine, Rua Manuel Bento de Sousa, n. ${ }^{\circ 3}$. 1169-201 Lisboa, Portugal, Tel: 00351 217804563, E-mail: cristiana. pereira@fmd.ul.pt

Citation: Gonçalves AF, Diamantino F, Pestana D, Palmela Pereira C (2015) The Medico-Legal Importance of Establishing Human Identity by Palatal Rugoscopy: Evaluation of the Immutability and Individuality of Palatal Rugae under the Influence of Ante Mortem Orthodontic Treatment. J Forensic Sci Criminol 3(3): 303 . doi: 10.15744/2348-9804.3.303

Received Date: April 10, 2015 Accepted Date: June 29, 2015 Published Date: June 30, 2015

\begin{abstract}
Introduction: The palatal rugae can be an alternative method of forensic identification. Through the years, several investigations focused on the effect of orthodontic treatment in the palatal rugae pattern.

Objectives: Evaluate the concepts of immutability and individuality of the palatal rugae in a Portuguese adult population submitted to orthodontic treatment, for the purpose of medico-legal identification through Thomas and Kotze classification system. Additionally, we wanted to establish comparison of the palatal rugae of each subject, and between genders.
\end{abstract}

Materials and Methods: Thirty three pairs of study dental casts, from thirty three patients submitted to orthodontic treatment in the Department of Orthodontics in College of Dentistry - University of Lisbon, were photographed and classified according to the classification system described by Thomas and Kotze. We proceeded to a statistical analysis running SPSS for Windows, version 20.0, using descriptive analysis and tests, with an inclusion level $\mathrm{p}<0.05$. The tests applied were normality tests and $\mathrm{T}$ Student for paired samples.

Results: The number and length of primary rugae remain identical when comparing the situation before and after orthodontic treatment. The number of secondary rugae decreases after orthodontic treatment. The variation of the angle of divergence was not statistically significant. The area of primary rugae presented statistically significant reduction after orthodontic treatment. There has no statistically significant differences between genders for total number number of rugae or average length of primary rugae ( $\mathrm{p}$ $<0.05$ ).

Discussion and Conclusion: The palatal rugae pattern does not remain stable after orthodontic treatment, and this refutes the supposed long term stability of the palatal rugae pattern. Therefore, it influences the ability to establish a positive medico-legal identification of a recent copse, if the person was submitted to ante mortem orthodontic treatment. The identification might still be possible if we possess a last ante mortem palatal record in these situations, to allow identification based on positive individual characteristics, through comparison with the post-mortem record. Considering gender, no statistically significant differences were found. This subject remains controversial and deserves further research.

Keywords: Medico-legal identification; Forensic Dentistry; Rugoscopy; Palatal rugae; Thomas and Kotze; Orthodontic treatment

\section{Introduction}

The palatal rugae can be an alternative method of forensic identification in cases such as car accidents, terrorist acts or mass disasters on which it's difficult to identify an individual through fingerprints or dental records or cases of recent corpses total or partially mutilated $[1,2]$.

The linear dimensions of the palatal rugae are altered during the normal growth of an individual in a way that is statistically significant $[3,4]$. 
The anatomical position of the palatal rugae inside the oral cavity, keep them protected from trauma and high temperatures. For those reasons, palatal rugae can be used as reference points during medico-legal identification [5-8].

Not even diseases, quimical aggression or trauma seem to be capable of altering the shape of the palatal rugae [9].

For that, the possibility of human identification through the study of the palatal mucosa became relevant, specially the palatal rugae for its stability, immutability, inalterability and variability, and because they are possible to classify [10-12]. Through the years, several investigations focused on the effect of orthodontic treatment in the palatal rugae pattern. Some authors concluded that orthodontics affected significantly the possibility of positive identification of individuals [2].

The objective of this investigation was to analyze the palatal rugae pattern in a population submitted to orthodontic treatment. The intent was to evaluate the individuality and immutability of the palatal rugae in this situation. Which means, if patients treated with orthodontics, had significant alterations in their palatal rugae pattern in a way that compromises medico-legal identification.

\section{Objectives}

The main objective of this investigation was to evaluate the concepts of immutability and individuality of the palatal rugae in a Portuguese adult population submitted to orthodontic treatment, for the purpose of medico-legal identification through Thomas and Kotze system of classification. It was compulsory to formulate two distinct experimental hypotheses:

\section{Immutability}

H0: The classification of the palatal rugae pattern according to Thomas and Kotze system, through analysis of photographs of dental casts, in a pre-orthodontics situation, is not significantly different of the classification of the palatal rugae pattern according to Thomas and Kotze system, through analysis of photographs of dental casts in a post orthodontics situation.

H1: The classification of the palatal rugae pattern according to Thomas and Kotze system, through analysis of photographs of dental casts, in a pre-orthodontics situation, is significantly different of the classification of the palatal rugae pattern according to Thomas and Kotze system, through analysis of photographs of dental casts in a post orthodontics situation.

\section{Individuality}

H0: The individual classification of the palatal rugae pattern according to Thomas and Kotze system, through analysis of photographs of dental casts in pre and post orthodontics situations, on each subject, is not significantly different.

H1: The individual classification of the palatal rugae pattern according to Thomas and Kotze system, through analysis of photographs of dental casts in pre and post orthodontics situations, on each subject, is significantly different.

The secondary objective of the investigation consisted in a comparison of the palatal rugae of each subject, classified according to Thomas and Kotze system, for medico-legal identification procedures in a Portuguese adult population. It was compulsory to formulate the following experimental hypothesis:

H0: The individual classification of the palatal rugae pattern according to Thomas and Kotze system, through analysis of photographs of dental casts, does not present significantly different individualizing characteristics in medico-legal identification.

H1: The individual classification of the palatal rugae pattern according to Thomas and Kotze system, through analysis of photographs of dental casts, presents significantly different individualizing characteristics in medico-legal identification.

\section{Objectives}

The palatal rugae were classified according to a system proposed by Thomas and Kotze [13] (Tables 1 and 2).

\begin{tabular}{|c|c|}
\hline Right side & Left side \\
\hline Total number of palatal rugae & Total number of palatal rugae \\
\hline Number of Primary Rugae (Type P) ${ }^{\star} 1$ & Number of Primary Rugae (Type P) ${ }^{\star} 1$ \\
\hline Number of Secondary Rugae (Type S) 1 & Number of Secondary Rugae (Type S) ${ }^{\star} 1$ \\
\hline Number of Fragmentary Rugae (Type F) & Number of Fragmentary Rugae (Type F) ${ }^{\star} 1$ \\
\hline Lenght of Rugae Type P & Lenght of Rugae Type P \\
\hline Lenght of Rugae Type S & Lenght of Rugae Type S \\
\hline Area of Primary Rugae & Area of Primary Rugae \\
\hline $\begin{array}{c}\text { Angle of Divergence "Last Rugae Type } \\
\text { P/S - median palatal suture" }\end{array}$ & $\begin{array}{c}\text { Angle of Divergence "Last Rugae Type } \\
\text { P/S - median palatal suture" }\end{array}$ \\
\hline
\end{tabular}

${ }^{*}$ - See Table 2.

Table 1: variables evaluated (part of Thomas and Kotze Classification System) 


\begin{tabular}{|c|c|}
\hline Type of Rugae & Length \\
\hline Primary Rugae (Type $\mathrm{P}$ ) & $5 \mathrm{~mm}$ or over \\
\hline Secondary Rugae (Type $\mathrm{S}$ ) & 3 to $5 \mathrm{~mm}$ \\
\hline Fragmentary Rugae (Type F) & 2 to $3 \mathrm{~mm}$ \\
\hline \multicolumn{2}{|c|}{ Rugae with less than $2 \mathrm{~mm}$ lenght are disregarded. } \\
\hline
\end{tabular}

Table 2: Classification of Rugae: three types - according to linear length

The situation, before and after orthodontic treatment, in photographs of dental casts, was compared.

To investigate the experimental hypothesis, a pilot study was designed. It consisted in the first stage of a wider research project, being developed in the College of Dentistry University of Lisbon. The study dental casts used belong to the Department of Orthodontics from that same College, and they represent the initial (before treatment) and final (after treatment) situation of the patients submitted to orthodontic treatment. The records were taken by different operators, residents of the Post Graduate Program in Orthodontics, before beginning treatment and immediately after removing the orthodontic appliances.

The research protocol for this investigation was approved by the Scientific Council of the School. The patient's privacy was assured.

The population sample comprehended thirty three patients, fourteen females and nineteen males, with a mean age of fifteen years old. This population was selected according to the following inclusion criteria:

\begin{tabular}{|c|c|}
\hline Dental Parameters & Identifying Parameters \\
\hline $\begin{array}{l}\text { - Presence of upper incisors (central and lateral, } 1^{\text {st }} \text { and/or } 2^{\text {nd }} \\
\text { quadrants); } \\
\text { - Presence of upper canine ( } 1^{\text {st }} \text { and/or } 2^{\text {nd }} \text { quadrants); } \\
\text { - Had been submitted to orthodontic treatment in University of Lis- } \\
\text { bon Post Graduate Program, independent of duration or modality }\end{array}$ & $\begin{array}{l}\text { - Caucasian afinity; } \\
\text { - Portuguese nationality; } \\
\text { - Portuguese naturality; } \\
\text { - } 1^{\text {st }} \text { degree siblings (parents) with Portuguese } \\
\text { nationality and naturality }\end{array}$ \\
\hline
\end{tabular}

The collected data collected from the clinical files was the following: number of file, age, sex, initial dental cast date (pre orthodontics) and final dental cast date (post orthodontics). Each subject and respective set of data was randomly numbered, and the data kept hidden from the evaluator during the observations, in a document separated from the observations records.

The dental casts were individually photographed with a Nikon D90, placed one at a time over a felt cloth and under suited natural illumination, with a sensibility ISO scale in place (Figure 1).

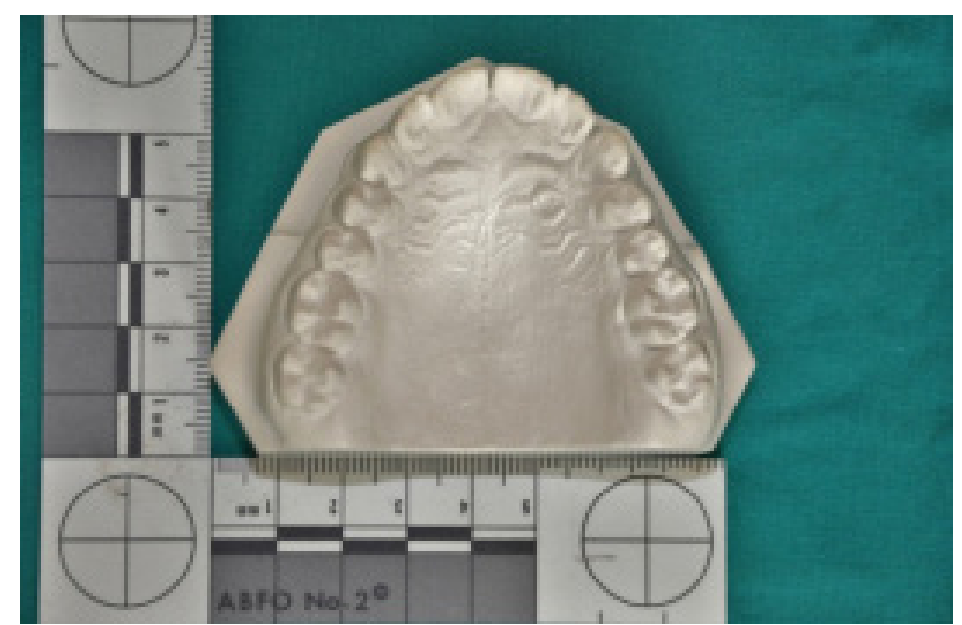

Figure 1: A photograph of a study dental cast obtained during the study

Before beginning the observation and classification of the photographs, these were randomly ordered. The classification was applied by a single evaluator.

The data records were done through analyze of the photographs of thirty three pairs of dental casts which reflected each patient's situation before and after orthodontic treatment. These photographs were analyzed with the image editor program Adobe Photoshop.

The photographs were classified according to the variables described by the authors Thomas and Kotze [13]. This system includes mostly quantitative variables; those analyzed are expressed in Tables 1 and 2 . Figures $2 \mathrm{a}-2 \mathrm{~g}$ shows an example of the experiment sequence in Adobe Photoshop. 


\section{Data analysis statistic methodology}

The data was collected directly in a computer file. The measurements in the photography were done using the ruler from Photoshop, divided by a constant value $(\mathrm{K})$ of 2,39 (equivalent to $1 \mathrm{~cm}$ in the ISO scale measured with the digital ruler) in order to obtain the real length, rounded to centesimal values.

We proceeded to a statistical analysis with SPSS for Windows, version 20.0, using descriptive analysis and tests, with an inclusion level $\mathrm{p}<0.05$. The tests applied were normality tests and T Student for paired samples.

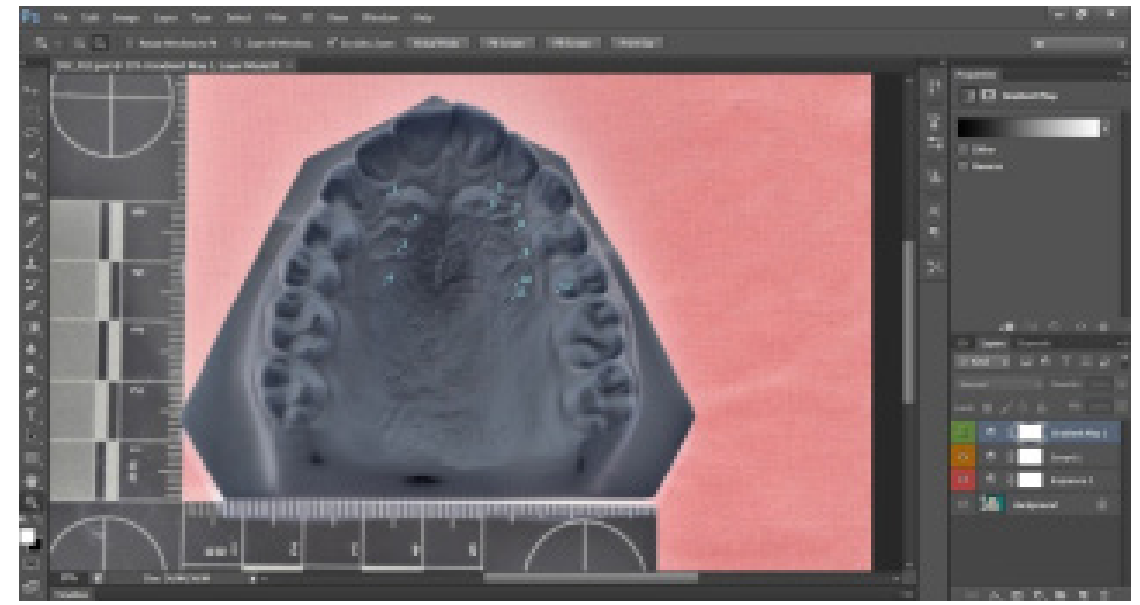

Figure 2a

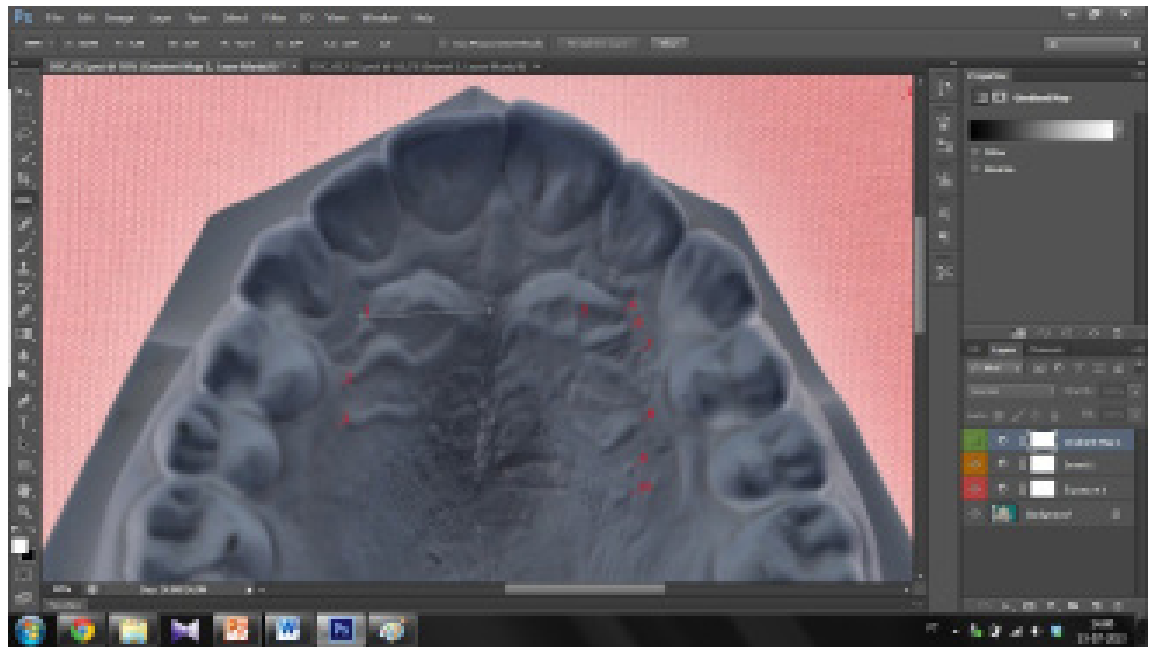

Figure 2b

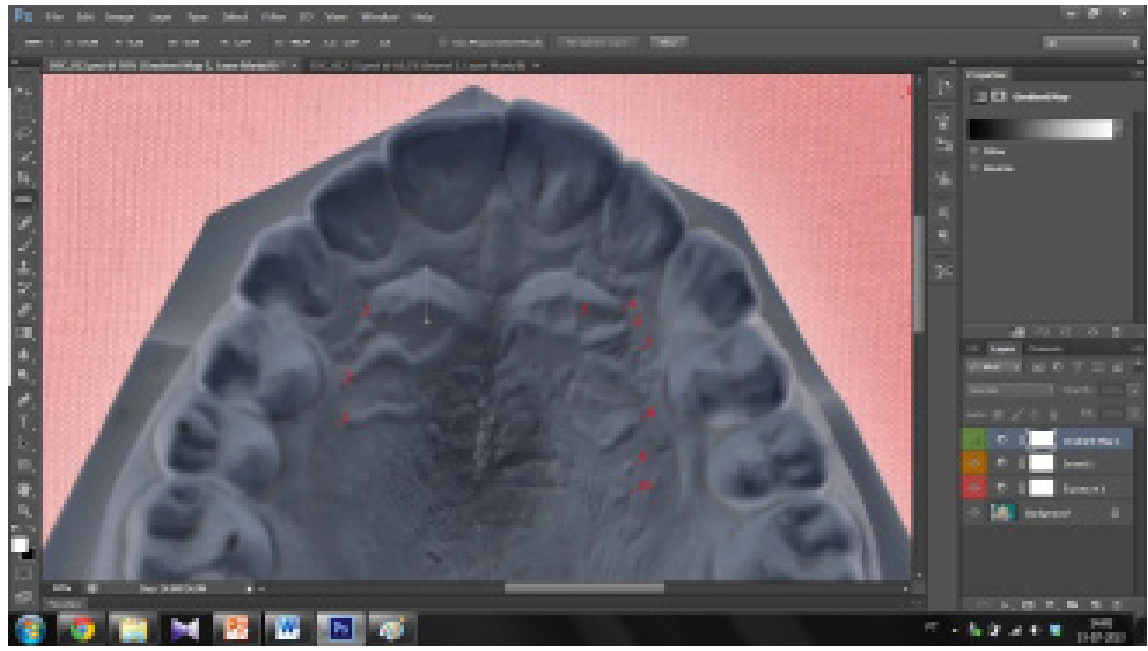

Figure 2c 


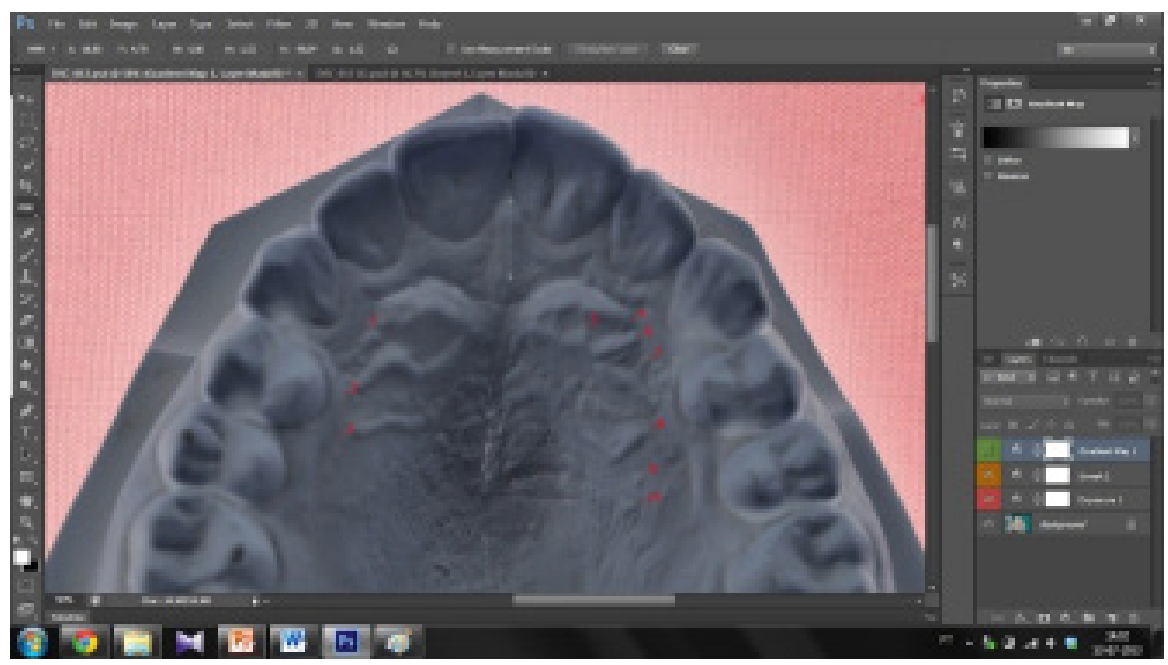

Figure 2d

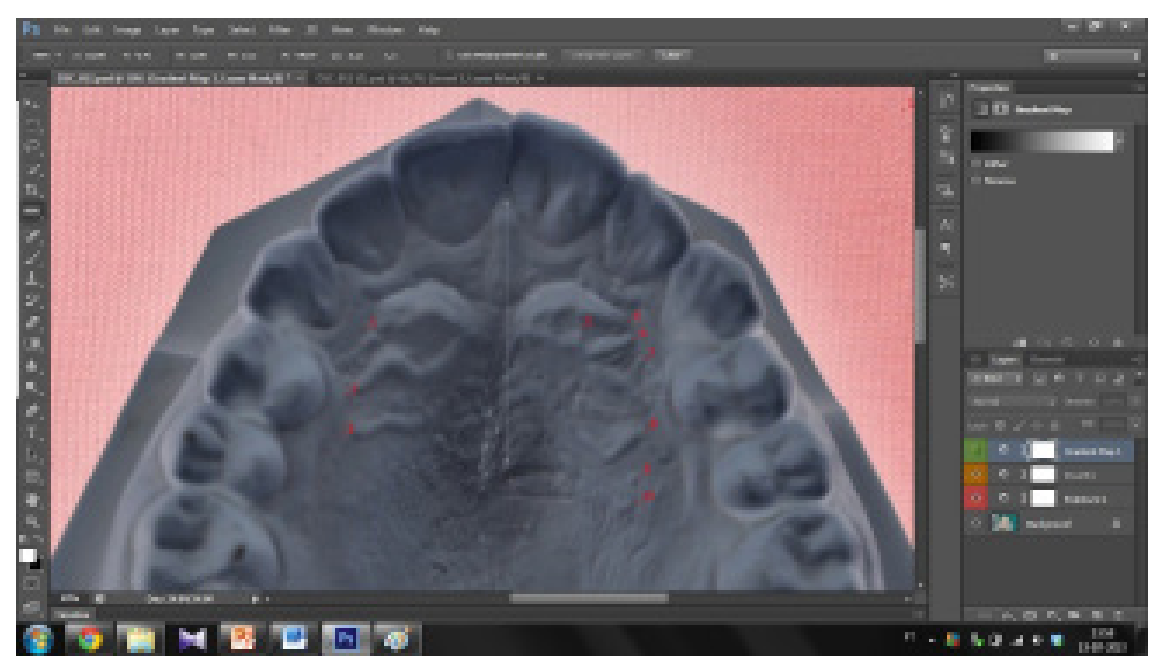

Figure 2e

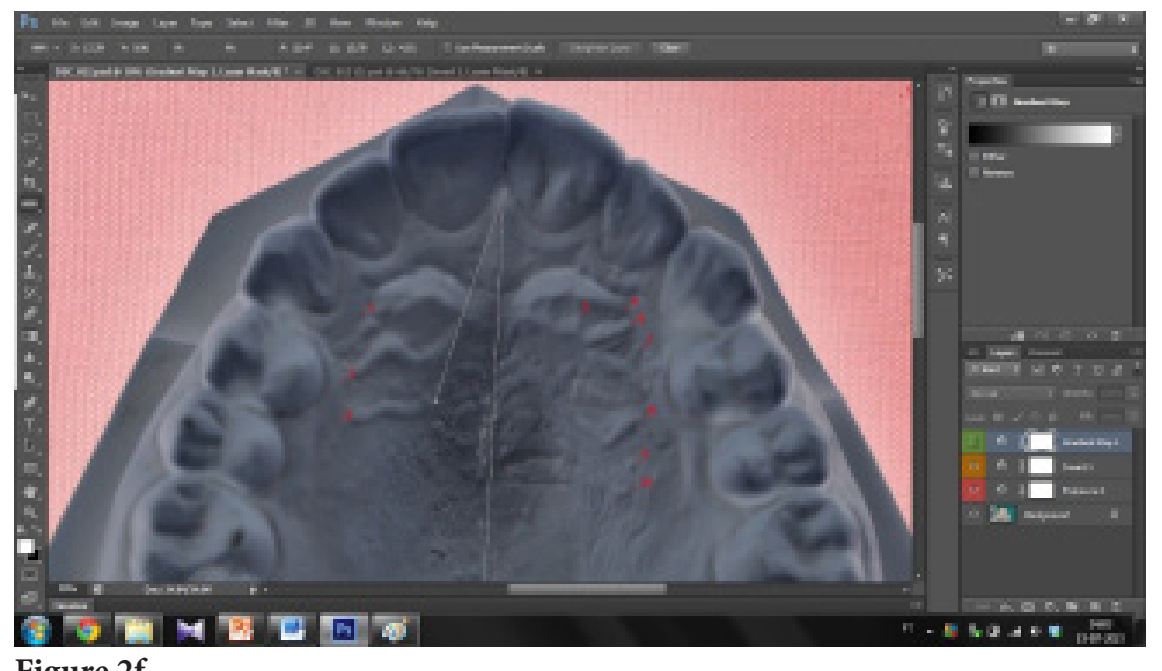

Figure 2f 


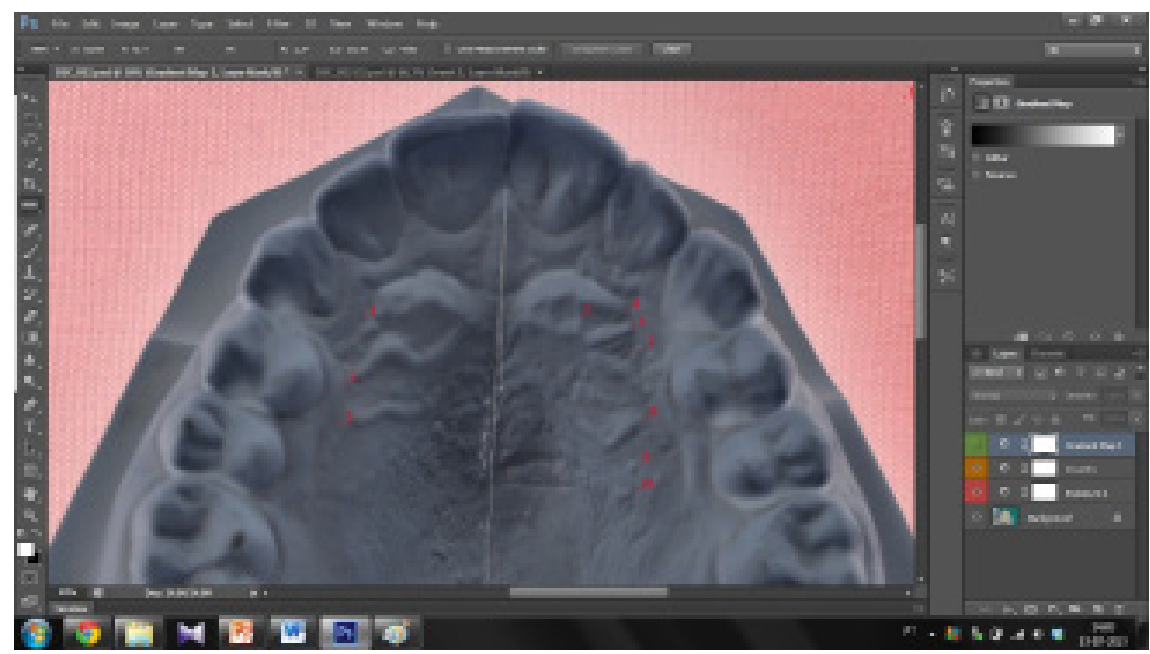

Figure $2 g$

Figures 2a-2g: Photograph of a study dental cast before orthodontic treatment during analysis in Adobe Photoshop to assess the variables described in Table 1 . Ruler function in the software was previously calibrated by comparison with the ISO scale measured on the photograph.

After applying the adequate shade and contrast filters to allow visual identification of the palatal rugae by the operator, rugae were identified with numbers in antero-posterior order (Figure 2a). Horizontal (length) and vertical (width) measurements taken to classify rugae in primary, secondary or fragmentary, and to calculate the area of the primary rugae (Figure 2b, 2c, Table 2). Distance from the most anterior part of the incisive papilla to the most anterior area of the rugae pattern (Figure 2d). Distance from the most anterior part of the incisive papilla to the most posterior part of the last primary/secondary rugae (Figure 2e). Divergence angle formed by the lines represented by the median palatal suture and the most posterior primary/secondary rugae, left and right sides (Figure 2f, 2g).

\section{Validation of data methodology}

On this study the measurements were executed by the same evaluator, avoiding the introduction of inter observator variability, although it remains dependent of a posterior evaluation of the intra observator variability due to the introduction of random errors.

And so, to verify the validity of the gathered data by this evaluator, a repetition of $10 \%$ of the observations was done after three months passed from the initial observations, to eliminate memory effect.

\section{Results}

The average total number of palatal rugae, for both palatal sides, is identical in pre and post orthodontic treatment situations (approximately 5-6 rugae) (Table 3 and Graph 1).

\begin{tabular}{|c|c|c|c|c|}
\hline \multicolumn{5}{|c|}{ Total Number of Palatal Rugae } \\
\hline \multirow{2}{*}{ Palatal Side } & Situation & Mean (N=33) & Std. Deviation & Std. Error Mean \\
\hline \multirow{2}{*}{ Right } & Pre Ortho & 5,45 & 1,003 &, 175 \\
\cline { 2 - 5 } & Post Ortho & 5,18 & 1,211 &, 211 \\
\hline \multirow{2}{*}{ Left } & Pre Ortho & 5,82 & 1,380 &, 240 \\
\cline { 2 - 5 } & Post Ortho & 5,45 & 1,301 &, 227 \\
\hline
\end{tabular}

Pre Ortho: before orthodontic treatment.

Post Ortho: after orthodontic treatment

Table 3: Total number of Palatal Rugae 


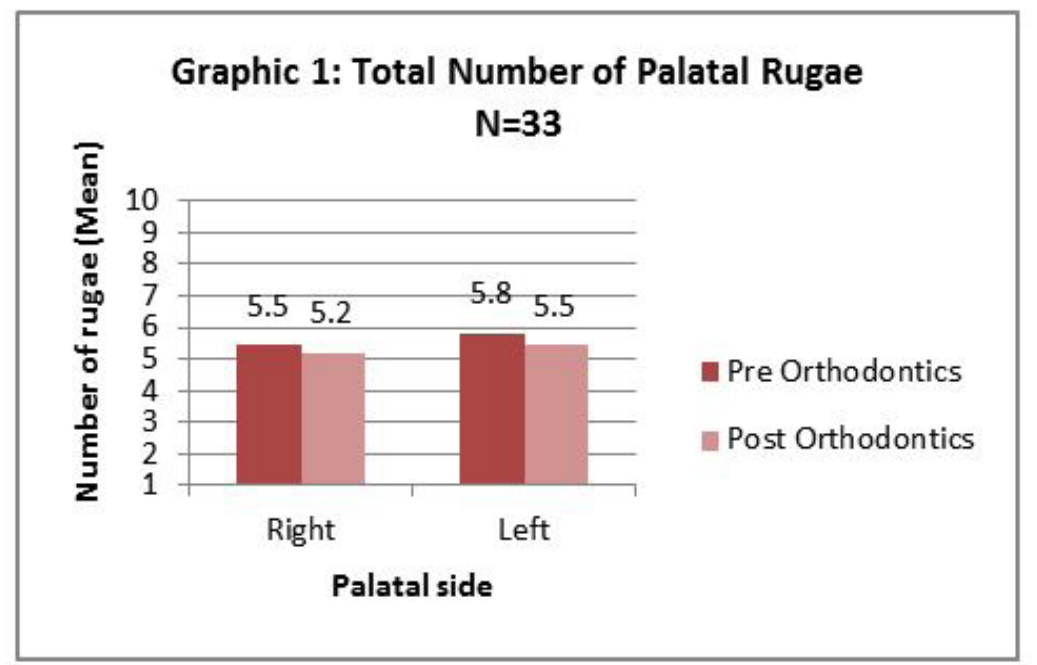

- The mean length of primary rugae, in both sides, is identical after orthodontic treatment. (Approximately $0.92 \mathrm{~cm}$ right side, $0.90 \mathrm{~cm}$ left side) (Table 4).

\begin{tabular}{|c|c|c|c|c|c|c|}
\hline \multicolumn{7}{|c|}{ Length of Primary Rugae (Type P) } \\
\hline \multirow{2}{*}{ Palatal Side } & Situation & Mean (N=33) & Std. Deviation & Std. Error Mean & Correlation & Sig. \\
\hline \multirow{2}{*}{ Right } & Pre Ortho &, 92089 &, 198726 &, 034594 & \multirow{2}{*}{, 773} &, 000 \\
\cline { 2 - 8 } & Post Ortho &, 92329 &, 227763 &, 039648 &, 00 \\
\hline \multirow{2}{*}{ Left } & Pre Ortho &, 90544 &, 142123 &, 024740 & \multirow{2}{*}{, 006} \\
\cline { 2 - 8 } & Post Ortho &, 90808 &, 167531 &, 029163 & & \\
\hline
\end{tabular}

Pre Ortho: before orthodontic treatment

Post Ortho: after orthodontic treatment

Table 4: Length of Primary Rugae (Type P)

- The average area of primary rugae decreases in post orthodontic situation, when comparing to pre orthodontic length, for both palatal sides (Table 5 and Graph 2).

- The average angle of divergence increases in the right side of the palate after orthodontic treatment, but decreases in the left side (Table 5 and Graph 3).

\begin{tabular}{|c|c|c|c|c|c|}
\hline \multicolumn{6}{|c|}{ Area of Primary Rugae and Angle of Divergence } \\
\hline Variable & Palatal Side & Situation & Mean $(\mathrm{N}=33)$ & Std. Deviation & Std. Error Mean \\
\hline \multirow{4}{*}{ Area of Primary Rugae } & \multirow{2}{*}{ Right } & Pre Ortho &, 25780 & ,095492 & 016623 \\
\hline & & Post Ortho & ,20856 & ,057364 & 009986, \\
\hline & \multirow{2}{*}{ Left } & Pre Ortho &, 25423 & 053649 & ,009339 \\
\hline & & Post Ortho & ,21894 & ,063337 & ,011026 \\
\hline \multirow{4}{*}{ Angle of Divergence } & \multirow{2}{*}{ Right } & Pre Ortho & 14,3424 & 7,31843 & 1,27397 \\
\hline & & Post Ortho & 16,1727 & 8,65250 & 1,50621 \\
\hline & \multirow{2}{*}{ Left } & Pre Ortho & 16,9606 & 8,12888 & 1,41506 \\
\hline & & Post Ortho & 15,7455 & 8,51664 & 1,48256 \\
\hline
\end{tabular}

Pre Ortho: before orthodontic treatment

Post Ortho: after orthodontic treatment

Table 5: Area of Primary Rugae and Angle of Divergene 

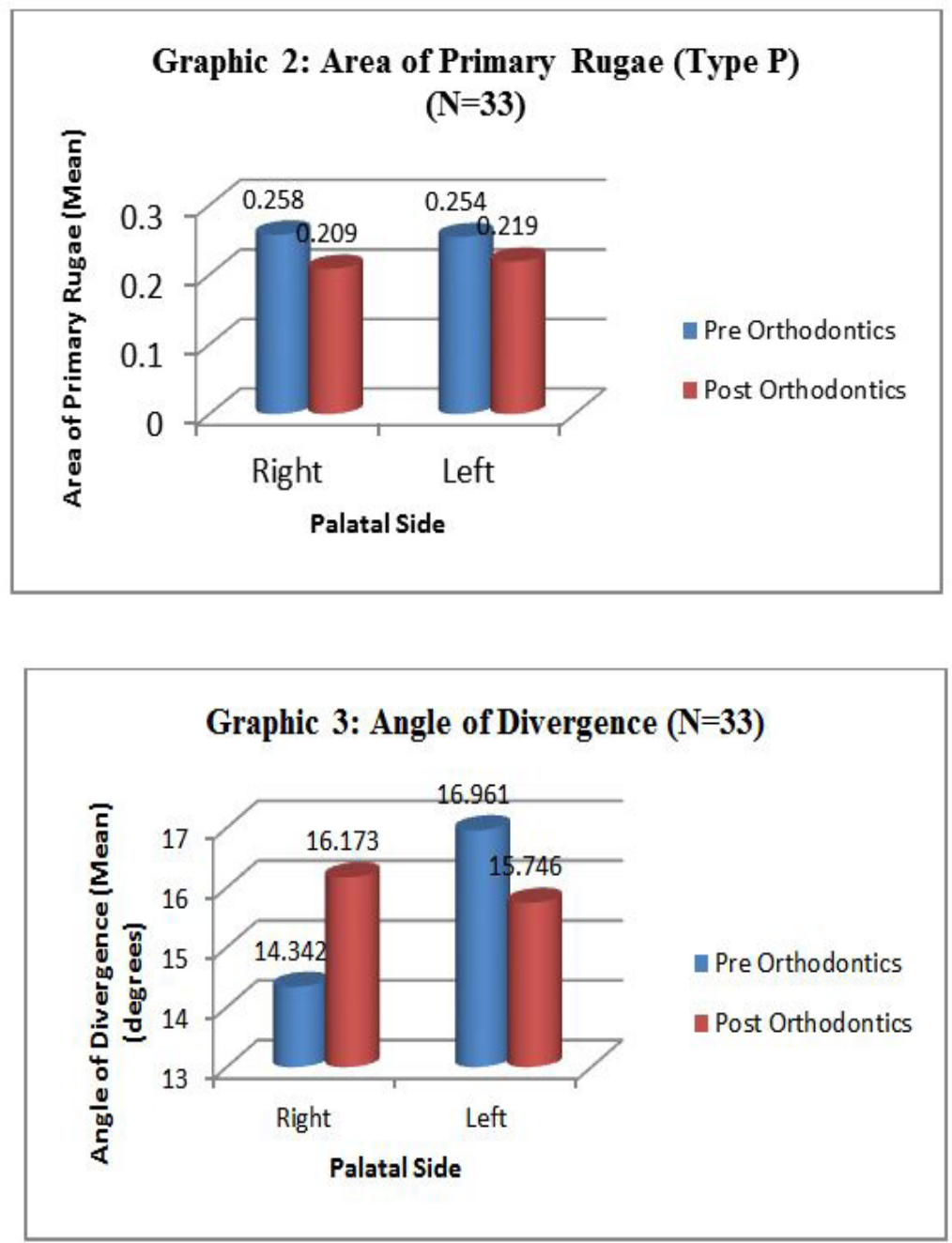

- The mean number of secondary rugae decreases, in both palatal sides, after orthodontic treatment, when comparing to pre orthodontics situation (Table 6 and Graph 4).

\begin{tabular}{|c|c|c|c|c|}
\hline \multicolumn{5}{|c|}{ Number of Secondary Rugae (Type S) } \\
\hline \multirow{2}{*}{ Palatal Side } & Situation & Mean (N=33) & Std. Deviation & Std. Error Mean \\
\hline \multirow{2}{*}{ Right } & Pre Ortho & 1,33 & 1,164 &, 203 \\
\cline { 2 - 5 } & Post Ortho & $\mathbf{1 , 1 8}$ & 1,131 &, 197 \\
\hline \multirow{2}{*}{ Left } & Pre Ortho & 1,48 & 1,326 &, 231 \\
\cline { 2 - 5 } & Post Ortho & $\mathbf{1 , 3 0}$ & 1,237 &, 215 \\
\hline
\end{tabular}

Pre Ortho: before orthodontic treatment Post Ortho: after orthodontic treatment

Table 6: Number of Secondary Rugae (Type S) 


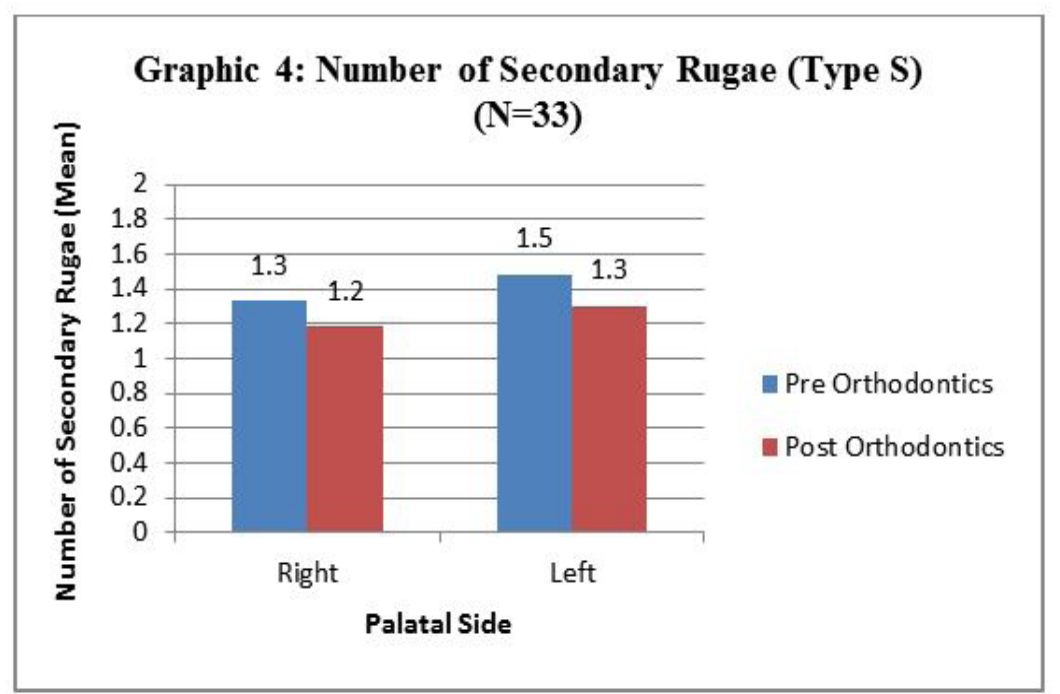

Comparing the mean total number of palatal rugae in pre and post orthodontic situations, paired differences to left and right sides, there was no statistically significant difference on any of the sides tested (Table 7).

\begin{tabular}{|c|c|c|c|c|c|c|c|c|c|}
\hline \multicolumn{10}{|c|}{ Total Number of Palatal Rugae } \\
\hline \multirow{3}{*}{$\begin{array}{l}\text { Palatal } \\
\text { Side }\end{array}$} & \multicolumn{6}{|c|}{ Paired Differences } & \multirow{3}{*}{$t$} & \multirow{3}{*}{ df } & \multirow{3}{*}{$\begin{array}{l}\text { Sig. } \\
\text { (2-tailed) }\end{array}$} \\
\hline & & \multirow[t]{2}{*}{ Mean } & \multirow{2}{*}{ Std. Deviation } & \multirow{2}{*}{ Std. Error Mean } & \multicolumn{2}{|c|}{$\begin{array}{c}95 \% \text { Confidence Interval } \\
\text { of the Difference }\end{array}$} & & & \\
\hline & & & & & Lower & Upper & & & \\
\hline Right & $\begin{array}{c}\text { TotRugaePREOrtho- } \\
\text { TotNRugaeTotPOS- } \\
\text { TOrtho }\end{array}$ &, 273 & 1,306 &, 227 &,- 190 & ,736 & 1,200 & 32 & ,239 \\
\hline Left & $\begin{array}{c}\text { TotRugaePreOrtho- } \\
\text { TotNRugaeTotPOS- } \\
\text { TOrtho }\end{array}$ & ,364 & 1,454 & ,253 &,- 152 & 879 & 1,437 & 32 &, 160 \\
\hline
\end{tabular}

TotRugaePREOrtho: total number of palatal rugae before orthodontic treatment

TotRugaePREOrtho: total number of palatal rugae after orthodontic treatment

Table 7: Total Number of Palatal Rugae: T Student Paired Samples (Pre versus Post Orthodontics)

The average length of primary rugae, in pre and post orthodontic situations, was the following: $0.93 \mathrm{~cm}$ right side pre orthodontics and $0.92 \mathrm{~cm}$ right side post orthodontics; $0.91 \mathrm{~cm}$ left side, both pre and post orthodontics. The comparison between pre and post orthodontic values showed no significant differences between average lengths of primary rugae for any of the sides tested. ( $\mathrm{p}=0,926$ right side, $\mathrm{p}=0,926$ left side), not allowing to confirm the stability of palatal rugae using this measurement (Table 8).

\begin{tabular}{|c|c|c|c|c|c|c|c|c|c|}
\hline \multicolumn{10}{|c|}{ Length of Primary Rugae (Type P) } \\
\hline \multirow{3}{*}{$\begin{array}{l}\text { Palatal } \\
\text { Side }\end{array}$} & \multicolumn{6}{|c|}{ Paired Differences } & \multirow{3}{*}{ t } & \multirow{3}{*}{ df } & \multirow{3}{*}{$\begin{array}{c}\text { Sig. } \\
\text { (2-tailed) }\end{array}$} \\
\hline & & \multirow{2}{*}{ Mean } & \multirow[t]{2}{*}{ Std. Deviation } & \multirow{2}{*}{ Std. Error Mean } & \multicolumn{2}{|c|}{$\begin{array}{c}95 \% \text { Confidence Interval } \\
\text { of the Difference }\end{array}$} & & & \\
\hline & & & & & Lower & Upper & & & \\
\hline Right & $\begin{array}{l}\text { LPRPREOrtho - LP- } \\
\text { PRPOSTOrtho }\end{array}$ &,- 002400 & , 146399 & ,025485 &,- 054311 & ,049511 &,- 094 & 32 & ,926 \\
\hline Left & $\begin{array}{l}\text { LPRPREOrtho - LP- } \\
\text { PRPOSTOrtho }\end{array}$ &,- 002635 &, 160805 &, 027993 &,- 059654 &, 054384 &,- 094 & 32 & ,926 \\
\hline
\end{tabular}

LPRPREOrtho: medium length of primary rugae after orthodontic treatment.

LPRPOSTOrth: medium length of primary rugae after orthodontic treatment.

Table 8: Length of Primary Rugae: T Student Paired Samples (Pre versus Post Orthodontics)

The comparison between pre and post orthodontic area of primary rugae, presented statistically significant reduction in post orthodontic situation, for both sides tested ( $\mathrm{p}=0,001$ right side, $\mathrm{p}=0,006$ left side) (Table 9).

The comparison between pre and post orthodontic angles of divergence, showed no significant difference in post orthodontic situation, for both sides tested ( $\mathrm{p}>0,05)$ (Table 9). 


\begin{tabular}{|c|c|c|c|c|c|c|c|c|c|}
\hline \multicolumn{10}{|c|}{ Area of Primary Rugae (Type P) and Angle of Divergence } \\
\hline \multirow{3}{*}{$\begin{array}{l}\text { Palatal } \\
\text { Side }\end{array}$} & & \multicolumn{5}{|c|}{ Paired Differences } & \multirow{3}{*}{$\mathbf{t}$} & \multirow{3}{*}{ df } & \multirow{3}{*}{$\begin{array}{c}\text { Sig. } \\
\text { (2-tailed) }\end{array}$} \\
\hline & & \multirow[t]{2}{*}{ Mean } & \multirow{2}{*}{ Std. Deviation } & \multirow[t]{2}{*}{ Std. Error Mean } & \multicolumn{2}{|c|}{$\begin{array}{c}95 \% \text { Confidence Interval } \\
\text { of the Difference }\end{array}$} & & & \\
\hline & & & & & Lower & Upper & & & \\
\hline Right & $\begin{array}{l}\text { APRPREOrtho - } \\
\text { APRPOSTOrtho }\end{array}$ & ,049243 &, 081314 &, 014155 &, 020411 & ,078076 & 3,479 & 32 &, 001 \\
\hline Left & $\begin{array}{l}\text { APRPREOrtho - } \\
\text { APRPOSTOrtho }\end{array}$ & ,035289 &, 068285 &, 011887 & ,011076 &, 059502 & 2,969 & 32 &, 006 \\
\hline Right & $\begin{array}{l}\text { ADivPREOrtho - ADi- } \\
\text { vPOSTOrtho }\end{array}$ & $-1,83030$ & 8,47133 & 1,47467 & $-4,83411$ & 1,17350 & $-1,241$ & 32 & ,224 \\
\hline Left & $\begin{array}{l}\text { ADivPREOrtho - ADi- } \\
\text { vPOSTOrtho }\end{array}$ & 1,21515 & 10,98178 & 1,91168 & $-2,67882$ & 5,10912 & ,636 & 32 & ,530 \\
\hline
\end{tabular}

APRPREOrtho: area of primary rugae before orthodontic treatment.

APRPOSTOrtho: area of primary rugae after orthodontic treatment.

ADivPREOrtho: angle of divergence (between the origin of the most posterior primary/secondary rugae and line that marks the palatal raphae) before orthodontic treatment.

ADivPOSTOrtho: angle of divergence (between the origin of the most posterior primary/secondary rugae and line that marks the palatal raphae) after orthodontic treatment.

Table 9: Area of Primary Rugae (Type P) and Angle of Divergence: T Student Paired Samples (Pre versus Post Orthodontics)

The comparison between pre and post orthodontic number of secondary rugae, paired differences to right and left sides, showed no statistically significant differences for any of the sides tested ( $p>0,05)$ (Table 10).

\begin{tabular}{|c|c|c|c|c|c|c|c|c|c|}
\hline \multicolumn{10}{|c|}{ Number of Secondary Rugae (Type S) } \\
\hline \multirow{3}{*}{$\begin{array}{l}\text { Palatal } \\
\text { Side }\end{array}$} & & \multicolumn{5}{|c|}{ Paired Differences } & \multirow{3}{*}{$\mathbf{t}$} & \multirow{3}{*}{ df } & \multirow{3}{*}{$\begin{array}{c}\text { Sig. } \\
(2-\text { tailed })\end{array}$} \\
\hline & & \multirow{2}{*}{ Mean } & \multirow{2}{*}{ Std. Deviation } & \multirow{2}{*}{ Std. Error Mean } & \multicolumn{2}{|c|}{$\begin{array}{l}\text { 95\% Confidence Interval } \\
\text { of the Difference }\end{array}$} & & & \\
\hline & & & & & Lower & Upper & & & \\
\hline Right & $\begin{array}{l}\text { NSRPREOrtho - NSR- } \\
\text { POSTOrtho }\end{array}$ & ,152 & 1,176 &, 205 &,- 265 &, 568 & ,740 & 32 & ,465 \\
\hline Left & $\begin{array}{l}\text { NSRPREOrtho - NSR- } \\
\text { POSTOrtho }\end{array}$ & ,182 & 1,758 & ,306 &,- 442 & ,805 &, 594 & 32 &, 557 \\
\hline
\end{tabular}

NSRPREOrtho: number of secondary rugae before orthodontic treatment.

NSRPOSTOrtho: number of secondary rugae after orthodontic treatment.

Table 10: Number of Secondary Rugae (Type S): T Student Paired Samples (Pre versus Post Orthodontics)

\section{Gender comparison}

- In average, the length of primary rugae is similar between males and females (Table 11).

- The average total number of rugae was higher in males than in females, for both sides of the palate (Table 12).

- Between males and females, the difference found in average length of primary rugae, and in total number of rugae, was not statistically significant $(\mathrm{p}>0,05)$.

\begin{tabular}{|c|c|c|c|c|c|c|}
\hline & & Gender & $\mathbf{N}$ & Mean & Std. Deviation & $\begin{array}{c}\text { Std. Error } \\
\text { Mean }\end{array}$ \\
\hline \multirow{4}{*}{$\begin{array}{l}\text { Average } \\
\text { length } \\
\text { Primary } \\
\text { Rugae }\end{array}$} & \multirow{2}{*}{ Right side } & Male & 19 & ,91697 & 209217 & ,047998 \\
\hline & & Female & 14 & ,92622 & , 191183 & ,051096 \\
\hline & \multirow{2}{*}{ Left side } & Male & 19 & ,93674 & 135978, & 031195 \\
\hline & & Female & 14 & ,86297 & 144030, & ,038494 \\
\hline
\end{tabular}

Table 11: Mean average length of primary rugae, by side of the palate and gender

\begin{tabular}{|c|c|c|c|c|c|c|}
\hline & & Gender & $\mathbf{N}$ & Mean & Std. Deviation & $\begin{array}{c}\text { Std. Error } \\
\text { Mean }\end{array}$ \\
\hline \multirow{4}{*}{$\begin{array}{l}\text { Aver- } \\
\text { age total } \\
\text { number } \\
\text { of rugae } \\
\text { (by side) }\end{array}$} & \multirow{2}{*}{ Right side } & Male & 19 & 5,89 & 1,329 & ,305 \\
\hline & & Female & 14 & 5,43 & ,938 & ,251 \\
\hline & \multirow{2}{*}{ Left side } & Male & 19 & 6,21 & 1,751 & ,402 \\
\hline & & Female & 14 & 5,93 & ,917 & 245 \\
\hline
\end{tabular}

Table 12: mean total number of rugae, by side of the palate and gender 


\section{Discussion}

Through the years, investigations aimed to discover to effect of orthodontic treatment in the palatal rugae pattern. Some authors concluded that orthodontics affected significantly the possibility of a positive identification of individuals $[2,14,15]$.

Our objective was to analyze the differences on palatal rugae pattern on thirty three patients submitted to orthodontic treatment.

Investigating the total number of rugae, for both palatal sides, there was no statistically difference between pre and post orthodontic palatal rugae pattern. These conclusions are supported by those from Kapali and colleagues [15], who said that the total number of rugae in an individual remains constant.

Concerning the application of Thomas and Kotze classification system, in terms of stability of the palatal rugae pattern, we concluded that the following differences were not statistically significant: total number of rugae, number of secondary rugae, length of primary rugae and angle of divergence.

These results are partially supported by Pateria and Thakkar [16], who also applied Thomas and Kotze classification system and concluded on their research that shape and size of palatal rugae were not significantly altered after orthodontic treatment.

Concerning the average length of primary rugae, the obtained result may oppose to Kapali and colleagues [15], who reported that the length of rugae increases significantly. However, that study approached the effects of age and not the effect of orthodontic treatment, so a direct comparison cannot be made.

Concerning the angle of divergence, the present study concluded its alteration in post orthodontics as non-significant. We didn't find results in published literature that could be directly compared to these findings. However, since the angle of divergence is formed between the median palatal suture and the medial point (origin) of the last primary/secondary rugae, we can establish parallelism with the results of previous research about stability of medial points of palatal rugae. The medial points of rugae were considered stable after orthodontic treatment in four of the studies reviewed $[3,4,17,18]$.

Simmons et al. [19], on the contrary, concluded that the medial points of palatal rugae suffered significant alteration after orthodontic treatment.

In the present investigation, the reduction of area of palatal rugae was statistically significant after orthodontic treatment. By definition, the average area of palatal rugae reflects the combination between a transversal dimension with an antero-posterior dimension, and these measurements were evaluated by Damstra and colleagues [14]. In that study, they concluded that rapid maxillary expansion devices induced a significant increase in the transversal measurements, but not in the antero-posterior measurements.

The possible opposition that might be established with our results is that the increase of transversal dimensions in the palatal rugae pattern increases its total area in cases of orthodontic treatment with rapid maxillary expansion.

The type of orthodontic devices used in each patient were not variables of this study, and we analyzed the area of primary rugae, then the direct comparison of our results with those from other authors would be imprecise. However, it is possible to infer that, both in case of the present project as in the author's case cited above, the palatal rugae pattern is not stable when the subjects are submitted to orthodontic treatment.

\section{Conclusion}

The palatal rugae pattern does not remain stable after orthodontic treatment, and this refutes the supposed long term stability of the palatal rugae pattern. Therefore, it influences the ability to establish a positive medico-legal identification of a recent copse, if the person was submitted to ante mortem orthodontic treatment. The identification might still be possible if we own a last ante mortem palatal record in this situations, to allow identification based on positive individual characteristics, through comparison with the post-mortem record.

There were no statistically significant differences between genders when comparing rugae characteristics. Although, since the relationship between gender and rugae pattern remains controversial, further research is recommended in this matter.

\section{Recommendations for future investigation}

- For the photographs to be adequate to classify the palatal rugae, the quality of the palatal region of the dental casts is an important factor;

- For bigger reproducibility and reliability during individual characterization, the implementation of comparison software for palatal rugae data would be strongly recommended;

- In the future, this pilot research might be developed and validated applying these methods to a wider sample of Portuguese population, to minimize the standard errors.

\section{Acknowledgement}

Research partially sponsored by national funds through the Fundação Nacional para a Ciência e Tecnologia, Portugal - FCT under the project (PEst-OE/MAT/UI0006/2014). 


\section{References}

1. O'Shaughnessy PE (2001) Introduction to forensic science. Dent Clin North Am 45: 217-27.

2. De Angelis D, Riboli F, Gibelli D, Cappella A, Cattaneo C (2012) Palatal rugae as an individualising marker: Reliability for forensic odontology and personal identification. Sci Justice 52: 181-4.

3. Almeida MA, Phillips C, Kula K, Tulloch C (1995) Stability of the palatal rugae as landmarks for analysis of dental casts. Angle Orthod 65: 43-8.

4. Kim HK, Moon SC, Lee SJ, Park YS (2012) Three-dimensional biometric study of palatine rugae in children with a mixed-model analysis: a 9-year longitudinal study. Am J Orthod Dentofacial Orthop 141: 590-7.

5. Saraf A, Bedia S, Indurkar A, Degwekar S, Bhowate R (2011) Rugae patterns as an adjunct to sex differentiation in forensic identification. J Forensic Odontostomatol 29: 14-9.

6. English WR, Robison SF, Summitt JB, Oesterle LJ, Brannon RB, et al. (1988) Individuality of human palatal rugae. J Forensic Sci 33: 718-26.

7. Kotrashetti VS, Hollikatti K, Mallapur MD, Hallikeremath SR, Kale AD (2011) Determination of palatal rugae patterns among two ethnic populations of India by logistic regression analysis. J Forensic Leg Med 18: 360-5.

8. Kallianpur S, Desai A, Kasetty S, Sudheendra U, Joshi P (2011) An anthropometric analysis of facial height, arch length, and palatal rugae in the Indian and Nepalese population. J Forensic Dent Sci 3: 33-7.

9. Pueyo VM, Garrido BR, Sánchez JAS (1994) Odontología Legal y Forense 277-92.

10. Briñón EN (2011) Palatograma Legal Programado. Rev. Circ. Argent. Odontol 68: 11-5.

11. Pereira C (2012) Medicina Dentária Forense, Primeira, (Lidel edn), Lisboa 71-9.

12. Mutalik VS, Menon A, Jayalakshmi N, Kamath A, Raghu AR (2013) Utility of cheiloscopy, rugoscopy, and dactyloscopy for human identification in a defined cohort. J Forensic Dent Sci 5: 2-6.

13. Thomas CJ, Kotze TJ (1983) The palatal ruga pattern: a new classification. J Dent Assoc S Afr 38: 153-7.

14. Damstra J, Mistry D, Cruz C, Ren Y (2009) Antero-posterior and transverse changes in the positions of palatal rugae after rapid maxillary expansion. Eur J Orthod 31: 327-32.

15. Kapali S, Townsend G, Richards L, Parish T (1997) Palatal rugae patterns in Australian aborigines and Caucasians. Aust Dent J $42: 129-33$.

16. Pateria AH, Thakkar K (2011) Palatal rugae a stable landmark-A comparison between pre and post orthodontic patients. Int J Dent Clin 3: 9-12.

17. Hauser G, Daponte A, Roberts MJ (1989) Palatal rugae. J Anat 165: 237-49.

18. Bailey LT, Esmailnejad A, Almeida MA (1996) Stability of the palatal rugae as landmarks for analysis of dental casts in extraction and nonextraction cases. Angle Orthod 66: 73-8.

19. Simmons JD, Moore RN, Erickson LC (1987) A longitudinal study of anteroposterior growth changes in the palatine rugae. J Dent Res 66: 1512-5.

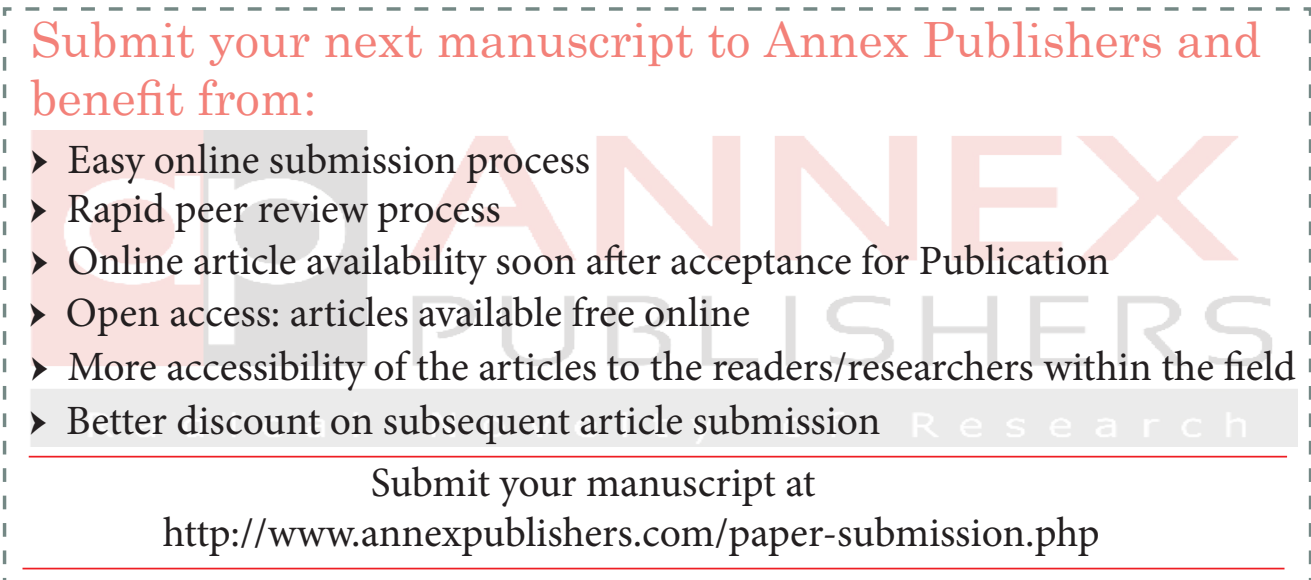

